\title{
PERENCANAAN KOMUNIKASI PEMASARAN WONDERFUL INDONESIA SEBAGAI PLACE BRANDING INDONESIA
}

\author{
Fasya Syifa Mutma, Reni Dyanasari \\ Prodi Ilmu Komunikasi Fakultas Humaniora dan Bisnis, Universitas Pembangunan Jaya \\ fasya.syifa@student.upj.ac.id, reni.dyanasari@upj.ac.id
}

\begin{abstract}
Tourism is a leading sector that became the foundation of the economy in Indonesia. As a leading sector, tourism plays an important role in increasing foreign exchange and expanding employment. Therefore, the government is focusing the tourism sector through marketing communication activities conducted by Kemenpar, one of them by using Wonderful Indonesia. Wonderful Indonesia is currently considered to have successfully promoted Indonesian tourism abroad. Because of the success, the researcher is interested to research about marketing communication planning conducted by Kemenpar by using qualitative approach and deep interview method. The results of this study indicate that Kemenpar performs all marketing communication planning steps covering three key resources, situation analysis, objectives, strategy, tactics, implementation and control that can support Indonesian place branding by fulfilling ten components in place branding. The findings in this research are Branding Advertising Selling (BAS) strategy which is always used for every marketing communication activity. In this strategy Kemenpar not only branding Wonderful Indonesia, but also tried to sell Indonesia tourism destinations.
\end{abstract}

Keywords : Wonderful Indonesia, Marketing Communication Planning, Place Branding

\begin{abstract}
ABSTRAK
Pariwisata merupakan sektor unggulan yang menjadi tumpuan ekonomi di Indonesia. Sebagai sektor yang diunggulkan, pariwisata berperan penting dalam meningkatkan devisa dan memperluas lapangan pekerjaan. Oleh karena itu, pemerintah sangat memfokuskan sektor pariwisata melalui kegiatan komunikasi pemasaran yang dilakukan oleh Kemenpar, salah satunya dengan menggunakan Wonderful Indonesia. Wonderful Indonesia saat ini dianggap telah berhasil mempromosikan pariwisata Indonesia ke mancanegara. Karena keberhasilan tersebut, Peneliti tertarik untuk meneliti mengenai perencanaan komunikasi pemasaran yang dilakukan oleh Kemenpar dengan menggunakan pendekatan kualitatif dan metode wawancara mendalam. Hasil penelitian ini menunjukkan bahwa Kemenpar melakukan semua langkah perencanaan komunikasi pemasaran yang meliputi tiga sumber daya kunci, analisis situasi, tujuan, strategi, taktik, implementasi dan kontrol yang dapat mendukung place branding Indonesia dengan memenuhi sepuluh komponen dalam place branding. Temuan dalam penelitian ini adalah strategi Branding Advertising Selling (BAS) yang selalu digunakan untuk setiap kegiatan komunikasi pemasaran. Dalam strategi ini Kemenpar tidak hanya mem-branding Wonderful Indonesia, namun juga turut berusaha untuk menjual destinasi pariwisata Indonesia.
\end{abstract}

Kata Kunci : Wonderful Indonesia, Perencanaan Komunikasi Pemasaran, Place Branding 


\section{PENDAHULUAN}

Pariwisata merupakan sektor yang saat ini tengah berkembang di Indonesia. Beragam daerah diberdayakan untuk pengembangan pariwisata guna meningkatkan kunjungan wisatawan. Pariwisata dapat membantu perekonomian Negara Indonesia karena dapat berkontribusi terhadap pendapatan devisa Negara, membuka lapangan pekerjaan, membuka kesempatan untuk pengembangan potensi dan kreatifitas masyarakat, serta dapat berpengaruh terhadap citra Negara Indonesia. Indonesia sendiri merupakan negara yang memiliki keindahan, mulai dari keindahan alam, sejarah hingga kebudayaannya. Indonesia terdiri dari deretan pulau indah dan beragam destinasi daratan yang dapat menjadi potensi besar untuk pengembangan pariwisata.

Sektor pariwisata Indonesia merupakan salah satu fokus yang sedang dijalankan oleh pemerintah (Media, 2017b). Pariwisata menyumbang 10\% PDB nasional; menduduki peringkat ke-4 penyumbang devisa nasional, sebesar 9,3\%; dan menyumbang 8,4\% lapangan kerja (Setkab.go.id, 2017). Pariwisata terus berkembang dan tumbuh dengan persentase yang terus menunjukkan peningkatan yang sangat signifikan.

World Economic Forum (WEF) yang mengeluarkan The Travel \& Tourism Competitiveness Report 2017 melaporkan bahwa Indonesia menduduki peringkat ke-47 dari 136 negara. Indonesia mengalami kenaikan 8 peringkat dimana dalam perhitungan sebelumnya menempati peringkat ke-50 dari 141 negara pada tahun 2015 (Setkab.go.id, 2017). Peringkat Indonesia yang meningkat tersebut membuktikan bahwa Pemerintah Indonesia telah melakukan berbagai usaha perbaikan terkait pariwisata mulai dari perbaikan sumber daya alam hingga pemberlakuan bebas visa untuk warga asing. Sehingga wisatawan semakin tertarik untuk mengunjungi Indonesia.

Kegiatan pariwisata merupakan kegiatan berkenaan dengan usaha memenuhi kebutuhan hidup manusia untuk memperoleh kesenangan. Pariwisata itu sendiri adalah suatu industri (Hakim, 2010, p. 2). Kondisi pariwisata yang saat ini tengah berkembang tentu didorong juga oleh usaha industri pariwisata untuk mengembangkan destinasi pariwisata di Indonesia.

Industri pariwisata menyediakan berbagai kebutuhan masyarakat terkait pariwisata guna memberikan kesenangan kepada para wisatawan. Industri pariwisata dapat diartikan sebagai usaha penyediaan barang dan jasa terkait pariwisata. Menurut Undang Undang no. 10 tahun 2009 tentang Kepariwisataan yang dikutip dari Riadi, 2015, usahausaha pariwisata dapat meliputi: daya tarik wisata; kawasan pariwisata; jasa transportasi pariwisata; jasa perjalanan wisata; jasa makanan dan minuman; penyediaan akomodasi; penyelenggaraan kegiatan hiburan dan rekreasi; penyelenggaraan pertemuan, perjalanan insentif, konferensi, dan pameran; jasa informasi pariwisata, jasa konsultan pariwisata, jasa pramuwisata, wisata tirta dan spa. 
Industri pariwisata akan menjadi tumpuan ekonomi Negara Indonesia. Pada tahun 2016 dengan target kunjungan wisatawan mancanegara mencapai 12 juta akan menyerap 11.700 tenaga kerja dan menghasilkan devisa sebesar Rp172,8 triliun (Warta Ekonomi, 2017). Kemudian pada tahun 2017, pariwisata berhasil mencatatkan devisa sebesar US\$17 miliar (Gumelar, 2017), angka ini setara dengan Rp230 triliun. Seperti gambar di bawah ini yang menunjukkan peningkatan kinerja pariwisata dari tahun 2015-2019.

Dengan bertambahnya jumlah kedatangan turis asing (baik turis maupun pebisnis asing) dikombinasikan dengan pertumbuhan PDB sebesar $+5 \%$ dan pertumbuhan investasi, ada permintaan yang meningkat untuk hotel dan kondominium dan juga tempat-tempat konferensi dan pameran. Apabila target pemerintah menyambut 20 juta turis asing pada 2020 tercapai maka ada kebutuhan besar untuk industri perhotelan di Negara ini. Terlebih lagi, Masyarakat Ekonomi ASEAN (MEA), yang dimulai pada akhir tahun 2015, mengimplikasikan hubungan dagang yang lebih intensif di wilayah ASEAN (Investment, 2016). Diberlakukannya MEA sejak 2015, membuat pendatang dari mancanegara meningkat berkaitan dengan hubungan dagangnya dengan Indonesia. Hal ini menyebabkan kebutuhan akomodasi pariwisata seperti penginapan dan kendaraan juga semakin meningkat.

Potensi pariwisata Indonesia harus dikelola dengan baik agar dapat menguntungkan Indonesia. Dikutip dari Instran.org (2016), pariwisata di Indonesia memang harus dikembangkan sebagai basis pengembangan ekonomi nasional. Mengingat telah ada Menteri Pariwisata yang memang bertugas untuk mengembangkan pariwisata nasional. Dari kutipan ini, dapat diketahui bahwa pengembangan pariwisata memang harus dilakukan mengingat pariwisata dapat memberikan keuntungan untuk ekonomi nasional Indonesia. Pengembangan pariwisata dilakukan oleh lembaga yang sudah ada yaitu Kementerian Pariwisata.

Instansi resmi Indonesia yang mengelola pariwisata adalah Kementerian Pariwisata Republik Indonesia (Kemenpar). Kemenpar adalah kementerian yang berada dibawah dan bertanggung jawab kepada Presiden. Kemenpar mempunyai tugas menyelenggarakan urusan pemerintahan di bidang kepariwisataan untuk membantu Presiden dalam menyelenggarakan pemerintahan Negara (Kemenpar.go.id, 2015).

Kementerian merupakan organisasi nonprofit pemerintah, yakni organisasi yang kegiatan operasionalnya dibiayai pemerintah atau Negara (Lspr.edu, 2014), dari kutipan tersebut dapat diketahui bahwa Kementerian Pariwisata juga merupakan organisasi nonprofit pemerintah yang tugasnya adalah mengurusi bidang pariwisata. Sebagai sebuah organisasi nonprofit pemerintah, Kemenpar juga perlu untuk melakukan komunikasi, khususnya komunikasi pemasaran. Dikutip dari sebuah Jurnal Ilmiah karya Ibrahim (2014), teknik komunikasi pemasaran dapat dimanfaatkan oleh lembaga pemerintahan untuk mempromosikan kebijakan demi meningkatkan perilaku positif masyarakat sesuai arah kebijakannya. 
Komunikasi pemasaran merupakan sebuah maksud dimana perusahaan berusaha menginformasi, membujuk, dan mengingatkan konsumen, secara langsung maupun tidak langsung, tentang produk dan merek yang mereka tawarkan (Keller, 2008, p. 230).

Sejak tahun 1980, usaha komunikasi pemasaran mulai dilakukan. Kemenpar telah melaksanakan usaha-usaha promosi dan komunikasi pemasaran untuk mengkomunikasikan destinasi pariwisata Indonesia, salah satu promosi yang cukup sukses yaitu Visit Indonesia Year. Dikutip dari artikel Hotel Management (2015), Kampanye promosi pariwisata Indonesia secara formal ditandai dengan dicanangkannya "Visit Indonesia Year (VIY)" pertama kali pada tahun 1991 seiring dengan dikeluarkannya Undang-undang Pariwisata No. 9 tahun 1990, yang dilanjutkan dengan Visit Indonesia Year 1992, 2008, 2009 dan 2010.

Kampanye Visit Indonesia Year dikatakan cukup berhasil karena dapat meningkatkan jumlah wisatawan yang pada awal kampanye hanya 2 juta kunjungan menjadi 6,4 juta kunjungan. Dikutip dari Mediatama (2008), target yang ditetapkan dari dilaksanakannya program Visit Indonesia 2008 berhasil tercapai, berdasarkan data Biro Pusat Statistik (BPS) dan Depbudpar, pencapaian jumlah wisatawan pada akhir tahun 2008 mencapai 6,433 juta orang.

Meskipun demikian, pemerintah menyayangkan kunjungan wisatawan masih tetap di angka 6 juta. Melihat hal tersebut pemerintah menganggap bahwa sektor pariwisata Indonesia harus memiliki slogan atau branding yang mencerminkan potensi yang dimiliki oleh Indonesia (Tourism in Frame, 2017).

Sehingga pada akhirnya, Kemenpar membuat branding pariwisata Indonesia untuk menjadi ujung tombak segenap upaya peningkatan pariwisata Indonesia, baik di dalam maupun luar negeri (Setkab.go.id, 2017). Branding pariwisata Indonesia adalah sebagaimana diperlihatkan pada dua brand yaitu Wonderful Indonesia (untuk konsumsi luar negeri dan dalam negeri) dan Pesona Indonesia (untuk konsumsi dalam negeri), dimana dalam penelitian ini peneliti mengambil objek yaitu Wonderful Indonesia. Wonderful Indonesia adalah sebuah brand yang dimiliki oleh Kemenpar untuk membranding Negara Indonesia di mancanegara.

Brand Wonderful Indonesia dipresentasikan melalui sebuah logo yang menyerupai gambar burung Garuda yang melambangkan hidup damai, terbuka, dan eksplorasi tanpa batas. Gambar burung Garuda tersebut dibentuk oleh lima goresan warna yaitu hijau, ungu, jingga, biru dan magenta. Kemudian diperjelas dengan tulisan "Wonderful Indonesia" yang menggunakan jenis huruf Signika, dan dipertegas/dipertebal pada tulisan "Indonesia" untuk mengedepankan dan memperkuat Indonesia diantara persaingan global. Dikutip dari Suara.com (2016) kata Wonderful atau Pesona mengandung janji bahwa Indonesia kaya dengan ketakjuban, dari segala aspek manusia 
maupun alamnya, yang mengusik kalbu dan menjanjikan pengalaman baru yang menyenangkan.

Dikutip dalam Setkab.go.id (2017) dalam buku panduan mengenai jenama resmi (official brand) yang disusun oleh Kemenpar tertulis bahwa terdapat lima pilar komunikasi tematik pesona di dalam brand Wonderful Indonesia. Kelima pesona tersebut adalah pesona alam (natural wonders); pesona cita rasa indrawi (sensory wonders); pesona budaya (cultural wonders); pesona kekinian (modern wonders); dan pesona petualangan (adventurous wonders). Kelima pesona tersebut memiliki kesatuan dengan apa yang disebut sebagai “Dunia Pesona” (World of Wonders), yakni Indonesia itu sendiri.

Menteri Pariwisata (Menpar) Arief Yahya menetapkan Wonderful Indonesia sebagai "country branding" atau yang disebut dalam penelitian ini adalah "place branding" yang wajib digunakan dalam setiap promosi pariwisata (Id.beritasatu.com, 2014). Place branding atau nation branding ini kemudian ditetapkan untuk menjadi branding untuk Pariwisata Indonesia.

Menurut Arief Yahya juga yang dikutip dari Media (2014) menyatakan bahwa satu brand besar bisa menjadi identitas dunia pariwisata. Brand "Wonderful Indonesia' sebagai place branding diharapkan dapat mempresentasikan daya tarik keindahan alam, keanekaragaman budaya dan keramahtamahan masyarakat Indonesia maupun fasilitas pariwisata menarik lainnya yang dikembangkan oleh orang kreatif Indonesia.

Tak hanya Indonesia, Negara-negara lain seperti Singapura, Thailand, dan Malaysia juga telah lebih awal meraih kesuksesan dalam melakukan usaha branding melalui pariwisata. Negara Singapura, yang pada tahun 2016 memiliki jumlah kunjungan wisatawan internasional sebanyak 16,4juta kunjungan ini (Marketplus, 2017), dikutip dari Kabarsurabaya.com (2017), baru saja meluncurkan brand baru untuk pariwisata yaitu "Singapore: Passion Made Possible" menggantikan brand lamanya yaitu "Your Singapore". Brand ini diharapkan dapat semakin menciptakan berbagai peluang baru dalam bisnis dan wisata sekaligus dapat semakin memperkenalkan Singapura sebagai Negara yang peduli akan passion para penduduknya. Brand Negara Singapura ini turut menjadi kompetitor Wonderful Indonesia.

Pada mulanya, brand Wonderful Indonesia pertama kali diluncurkan pada tahun 2011, kemudian mengalami beberapa reposisi terkait dengan pergantian Menteri Pariwisata menjadi Arief Yahya. Menteri Pariwisata kemudian memutuskan untuk mempertahankannya bahkan memperkuat pencitraannya di dalam maupun ke luar negeri. "Wonderful Indonesia" yang kini didampingi "Pesona Indonesia" secara resmi diluncurkan secara bersamaan pada tahun 2014 (Liputan6.com, 2015).

Sejak diluncurkan tahun 2014, Wonderful Indonesia dan Pesona Indonesia terus dipromosikan di dalam maupun di luar negeri. Dikutip dari Tribunnews, 2017, dan mulai 
2015 Wonderful Indonesia dipromosikan secara masif ke seluruh dunia. Menurut referensi World Economic Forum (WEF) di 2016 Wonderful Indonesia berada di peringkat 47 dunia atau mengalahkan brand Truly Asia Malaysia berada di peringkat 96 dan brand Amazing Thailand di peringkat 83 dunia.

\section{Identifikasi Masalah}

Tiga tahun terakhir sejak gencarnya usaha komunikasi pemasaran Wonderful Indonesia, kunjungan wisatawan nusantara \& mancanegara terdata meningkat tiap tahunnya. Brand Wonderful Indonesia pun semakin dikenal oleh masyarakat.

Dikutip dari Statistik Kemenpar.go.id (2017), data kunjungan wisatawan mancanegara (wisman) bulan Januari-Desember 2017 adalah sebesar 14 juta kunjungan, dimana jumlah kunjungan naik dari periode yang sama tahun sebelumnya yaitu sebesar 11,5 juta kunjungan. Kemudian dikutip dari Bella (2017) menurut data Kemenpar secara kumulatif sejak Januari-Oktober 2017 menunjukkan jumlah wisatawan nusantara (wisnus) mencapai 252.569.465. Menteri Pariwisata Arief Yahya memaparkan, jumlah wisnus Januari-Oktober 2017 lebih tinggi 14\% dibandingkan target yang ditetapkan sebesar 221,5 juta wisnus.

Tidak hanya meningkatkan kunjungan wisnus dan wisman, promosi pariwisata Indonesia dalam dua tahun terakhir juga telah memberikan sumbangan penghargaan untuk pariwisata Indonesia. Dikutip dari Farhan (2016), selama 2016, pariwisata Indonesia mendapat 31 penghargaan dari 22 negara. Beberapa penghargaannya seperti menang 12 kategori di World Halal Tourism Awards yang digelar di Abu Dhabi, penghargaan 'The Outstanding Liveaboard Diving Destination' di Diving and Resort Travel Expo Hong Kong, 'The Famous Next Travel Destination' dari China Travel and Leisure, hingga Travel Weekly Asia menempatkan Wonderful Indonesia sebagai The Best Destination Marketing 2016 di Singapura.

Kemudian tahun 2017, pariwisata Indonesia juga banyak menerima penghargaan seperti video pariwisata Wonderful Indonesia yang bertajuk "The Journey of a Wonderful World" yang menjadi juara kategori Video Competition 2017 Region East Asia and Pacific, dan People's Choice Award UNWTO yang merupakan ajang kompetisi video pariwisata di China. Kemudian Indonesia juga dinobatkan sebagai 'Destination of the Year' dalam ajang penghargaan The 28th Annual TTG Travel Awards 2017, di Bangkok, Thailand (Media, 2017a).

Indonesia menjadi destinasi terbaik pilihan pembaca Dive's Magazine dalam kategori destinasi selam terbaik dunia, di London, Inggris, Selain destinasi terbaik, Indonesia juga meraih juara dalam kategori Dive Center atau Resor Selam Terbaik. Kemudian, Bali memperoleh penghargaan Best Agent Choice Award dalam kategori Destination for Spa \& Wealthness yang diselenggarakan oleh majalah Selling Travel. Lalu dalam ajang $30^{\text {th }}$ ASEANTA Awards, Indonesia memboyong banyak kategori penghargaan. Antara lain 
kategori Best ASEAN Tourism Photo, Best ASEAN Airlines Program dan Best ASEAN Cultural Preservation Effort (Media, 2017a).

Selain itu, Indonesia turut menempati peringkat ke-47 dunia menurut WEF. Seperti gambar dibawah ini yang menunjukkan posisi Wonderful Indonesia diantara Negaranegara di Asia.

Gambar 1.

Performansi Wonderful Indonesia di Negara-negara Asia

\begin{tabular}{|c|c|c|}
\multirow{2}{*}{ Nation } & \multicolumn{2}{|c}{$\begin{array}{c}\text { Country Brand } \\
\text { Strategy rating } \\
\text { (max= 100) }\end{array}$} \\
\cline { 2 - 3 } & Rank & Point \\
\hline Jepang & 42 & 79.5 \\
India & 81 & 72.6 \\
Singapore & 38 & 79.7 \\
\hline Indonesia & $\mathbf{4 7}$ & $\mathbf{7 9 . 1}$ \\
\hline Hongkong & 17 & 84.8 \\
Korea & 52 & 78.7 \\
Thailand & $\mathbf{6 8}$ & $\mathbf{7 4 . 7}$ \\
Malaysia & $\mathbf{8 5}$ & $\mathbf{7 2 . 1}$
\end{tabular}

Gambar 1. Menggambarkan performansi Wonderful Indonesia di Negara-negara Asia yang menunjukkan bahwa Indonesia berada di peringkat 47. Diambil dari PPT Paparan, (Data Internal Kemenpar)

Peningkatan jumlah wisatawan, penghargaan dan peringkat brand yang naik terjadi setelah semakin digencarkannya promosi Wonderful Indonesia ke seluruh dunia (Indri, data wawancara informan). Hal ini merupakan sebuah pencapaian besar untuk Kemenpar berkat usaha untuk melakukan berbagai kegiatan komunikasi pemasaran. Kemenpar menerapkan strategi penguatan komunikasi pemasaran melalui semua channel komunikasi, digital, elektronik, cetak dan media luar ruang untuk terus mempromosikan destinasi wisata di Indonesia melalui place branding Wonderful Indonesia yang diharapkan mampu meningkatkan jumlah kunjungan wisatawan nusantara dan mancanegera.

Kemenpar menggunakan beragam media komunikasi seperti melalui promosi besarbesaran di media internasional (Antara News, 2016). Kemenpar juga berpartisipasi pada berbagai bursa pariwisata internasional. (Suara.com, 2016). Promosi media luar ruang juga dilakukan di Filiphina, Belanda, Jerman, Malaysia, sedangkan publikasi media online antara lain di Google, Youtube, TripAdvisor dan Baidu. Kementerian Pariwisata RI juga melakukan promosi dengan cara pemasangan TVC di 30 channel, serta pemasangan iklan media cetak di beberapa majalah (Suara.com, 2016). Selain usaha promosi melalui berbagai media dan kerjasama internasional, Kementerian Pariwisata RI turut melakukan co-branding dengan perusahaan dan pengusaha yang ada di Indonesia (Pesona Indonesia, 2017, Para. 7). Usaha-usaha komunikasi pemasaran ini dilakukan sekaligus untuk place branding Indonesia. 
Place branding merupakan fenomena menarik, kompleks dan kontroversial. Place branding dapat diterapkan dalam beragam bentuk (branding Negara, kota, benua, dan destinasi pariwisata) dan tidak dapat dipungkiri bahwa saat ini place branding telah dikembangkan di area studi akademis (Kavaratzis, Warnaby, Ashworth, 2015, p. 13).

Penjenamaan atau pemerekan atau pelabelan suatu negara (country branding atau nation branding) atau yang dalam penelitian ini disebut place branding adalah suatu hal yang sangat penting bagi suatu negara-bangsa (nation state), tidak terkecuali Negara Kesatuan Republik Indonesia (NKRI). Place branding sangat penting karena terkait erat dengan kepribadian (personality), jati diri (identity), citra (image), dan nama baik (reputation), bahkan kepercayaan (trust) negara-bangsa di mata dunia internasional. Kemudian kesemuanya akan bermuara pada pariwisata (tourism). Penjenamaan pariwisata negara (country branding atau nation branding) atau yang dalam penelitian ini disebut place branding dengan sendirinya akan meningkatkan nilai tambah (value added) negara tersebut (Setkab.go.id, 2017).

Usaha komunikasi pemasaran yang telah dilakukan membuat place branding Wonderful Indonesia menjadi semakin dikenal masyarakat, global maupun domestik, dan membuat citra pariwisata dan Indonesia menjadi bagus. Seperti yang dikutip dalam Liputan6.com (2017), menyatakan bahwa brand Wonderful Indonesia dipandang sudah kuat di Australia. Selain itu, branding Wonderful Indonesia telah menaikkan confidence bangsa Indonesia di mata dunia (GoAceh, 2017), karena brand pariwisata ini telah mendapatkan pengakuan dunia (Barat, 2017).

Kesuksesan komunikasi pemasaran yang dilakukan Kemenpar tidak lepas dari proses perencanaan komunikasi pemasaran yang baik. Mengingat bahwa dalam dunia pemasaran, perencanaan memainkan peran yang sangat penting dalam pengembangan dan pengimplementasian dari program promosi yang efektif (Belch \& Belch, 2012, p. 25). Pengembangan perencanaan ini juga membantu meminimalisir kesalahan dan memberikan efisiensi dan efektifitas dari suatu program pemasaran (Fill, 2009, p. 308). Maka berdasarkan latar belakang dan data yang telah di temukan, peneliti tertarik untuk mengetahui lebih dalam terkait bagaimana perencanaan komunikasi pemasaran yang dilakukan oleh Kementerian Pariwisata RI melalui Wonderful Indonesia sebagai place branding Indonesia.

\section{Rumusan Masalah \& Tujuan Penelitian}

Berdasarkan latar belakang dan identifikasi masalah di atas, maka rumusan masalah dalam penelitian ini adalah "Bagaimana perencanaan komunikasi pemasaran Wonderful Indonesia sebagai place branding Indonesia?"

Tujuan dari penelitian ini adalah untuk mengetahui dan menggambarkan bagaimana perencanaan komunikasi pemasaran Wonderful Indonesia sebagai place branding Indonesia. 


\section{TINJAUAN PUSTAKA}

Komunikasi pemasaran merupakan sebuah maksud dimana perusahaan berusaha menginformasi, membujuk, dan mengingatkan konsumen, secara langsung maupun tidak langsung, tentang merek yang mereka jual. Marketing communication merepresentasikan suara dari merek dan membangun hubungan dengan konsumen (Keller, 2008, p. 230). Menurut Keller terdapat elemen-elemen komunikasi pemasaran yang memiliki peran penting yaitu advertising, sales promotion, PR \& Publicity, Event Marketing \& Sponsorship, dan Personal Selling (Keller, 2008, p. 235-266).

\section{Perencanaan Komunikasi Pemasaran}

Terdapat banyak pendekatan yang berbeda untuk membuat perencanaan pemasaran, lebih khususnya perencanaan komunikasi pemasaran. SOSTAC yang dikemukakan oleh PR Smith (1998) adalah sebuah konsep sederhana yang dapat membantu managers untuk membangun kembali komponen kunci dari perencanaan komunikasi pemasaran. SOSTAC dapat diaplikasikan pada berbagai perencanaan, seperti perencanaan perusahaan, perencanaan pemasaran, perencanaan komunikasi pemasaran, perencanaan media sosial, perencanaan direct mail atau bahkan perencanaan pribadi (Smith \& Zook, 2011, p. 226).

SOSTAC memberikan gambaran dan struktur bagaimana perencanaan komprehensif dapat terbangun. SOSTAC dan the 3Ms (tiga sumber daya kunci) memberikan pendekatan sederhana untuk membangun sebuah perencanaan komunikasi pemasaran (Smith \& Zook, 2011, p. 226).

\section{The 3Ms}

Setiap perencanaan harus meliputi tiga sumber daya yaitu Men/women the human resources), pria/wanita maksudnya adalah sumber daya manusia, siapa yang diperlukan untuk melakukan sesuatu? Artinya pria dan wanita profesional dengan kemampuan mumpuni dan dapat menangani suatu kegiatan. Beberapa bisa didapatkan dalam organisasinya sendiri, namun ada juga yang menggunakan orang diluar organisasi seperti agensi untuk melakukan suatu pekerjaan. Money (budget), uang berarti budget. Terdapat beberapa cara dalam menentukan budget komunikasi pemasaran. Minutes (time), waktu adalah sumber daya yang paling terbatas. Skala waktu sangat penting. Tanpanya semua perencanaan akan menjadi tidak terkontrol (Smith \& Zook, 2011, p. 226-228).

\section{SOSTAC}

Analisis situasi harus dilakukan secara komprehensif. Analisis harus meliputi ulasan kinerja (penjualan, saham, dan profitabilitas) selama periode paling terbaru. Perbandingan dengan tahun sebelumnya memperlihatkan tren, dan perbandingan terhadap kompetitor memperlihatkan kinerja. Analisis harus berisi rangkuman ulasan 
dari keseluruhan kinerja pemasaran, pasar, persaingan, dan kekuatan dan kelemahan (Smith \& Zook, 2011, p. 229).

Perencanaan komunikasi pemasaran tidak mengharuskan adanya analisis SWOT yang lengkap, yang biasanya ditemukan di dalam perencanaan pemasaran yang lengkap. Analisis situasi dalam perencanaan komunikasi pemasaran harus tetap fokus pada aspek komunikasi seperti kinerja (mengidentifikasi elemen bauran komunikasi mana yang berfungsi paling baik), target pasar dan positioning. Diperlukan juga penjelasan tentang positioning dari produk atau jasa yaitu bagaimana produk tersebut dipersepsikan dalam benak target pasar (Smith \& Zook, 2011, p. 229).

Setelah melakukan analisis situasi yang dapat menggambarkan posisi suatu produk atau perusahaan. Langkah selanjutnya adalah mendefinisikan tujuan. Objektif yang jelas membuat control management menjadi lebih mudah. Menyusun objektif untuk pertama kalinya memang sulit, namun untuk kedepannya objektif yang telah disusun dapat membantu membuat perencanaan kerja menjadi lebih mudah. Membangun objektif yang jelas penting untuk memberikan fokus kepada organisasi. Objektif yang jelas juga memberikan arahan untuk usaha kreatif berikutnya (Smith \& Zook, 2011, p. 233).

Objektif dibagi menjadi dua tipe yaitu: marketing objectives dan communication objectives (Smith \& Zook, 2011, p. 233). Marketing objective mengarah kepada penjualan, saham, distribusi penetrasi, peluncuran produk baru, dan lain sebagainya (Smith \& Zook, 2011, p. 233).

Communication objectives mengarah kepada bagaimana komunikasi berdampak kepada pemikiran target audiens, seperti misalnya membangkitkan kesadaran, perilaku, ketertarikan atau percobaan. DAGMAR (defining advertising goals for measuring advertising responses) dan AIDA (attention, interest, desire, action) memberikan ukuran untuk communication objectives dengan mencoba memilah beragam tahap mental pembeli sebelum terjadi pembelian (Smith \& Zook, 2011, p. 234).

Tahap selanjutnya adalah strategi. Strategi merangkum terkait "bagaimana mencapai kesana" maksudnya adalah bagaimana objektif yang telah disusun dapat dicapai. Strategi menggerakkan taktik dalam arahan yang sama. Strategi merangkum taktik. Strategi komunikasi membantu mengharmonisasikan dan mengintegrasikan semua taktikal alat komunikasi. Strategi komunikasi dapat meliputi pilihan dari target pasar, positioning, pilihan alat komunikasi, rangkaian alat komunikasi (apakah alat yang berbeda digunakan pada tahap yang berbeda) dan lain-lain (Smith \& Zook, 2011, p. 235).

Strategi komunikasi yang baik membantu menjaga agar urutan taktis alat komunikasi dapat terintegrasi dan berpindah dalam arahan yang sama, menimbulkan dampak yang lebih besar dan mengurangi biaya. Cara sederhana untuk berlatih menulis strategi 
komunikasi pemasaran adalah dengan menghasilkan beberapa alternatif strategi agar pilihan strategi bisa menjadi pertimbangan (Smith \& Zook, 2011, p. 237).

Tahap selanjutnya adalah taktik. Taktik adalah perincian dari strategi. Dalam pemasaran, taktik komunikasi adalah alat komunikasi seperti advertising, PR, direct mail, dan lainlain. Taktik dalam perencanaan komunikasi pemasaran berisi list tentang apa, kapan, dan bagaimana saat pengimplementasian alat komunikasi (Smith \& Zook, 2011, p. 237).

Selanjjutnya tahap action. Tahap action mengungkapkan perincian dari taktik. Perencanaan perincian action membawa taktik kepada kehidupan. Action merupakan pengimplementasian taktik (Smith \& Zook, 2011, p. 237).

Perencanaan harus meliputi sistem kontrol yaitu bagaimana kinerja akan dimonitor, diukur dan dikendalikan. Sistem kontrol harus berada di tempat untuk membantu memonitor setiap kampanye atau aktifitas. Pemasar sekarang dapat mengukur dan membandingkan setiap aktifitas: inbound (kampanye media sosial), outbound marketing (kampanye periklanan), online dan offline. Jika kampanye berfokus untuk meningkatkan kesadaran terhadap brand dalam benak target audiens maka ini bisa diukur melalui survey. Jika kampanye berfokus kepada engagement dan penjualan maka ini bisa diukur dengan mengidentifikasi jika pengunjung atau pelanggan muncul dari tiap alat komunikasi - mengasumsikan kampanye berfokus pada peningkatan level engagement, seperti interaksi dalam situs web atau media sosial, pendaftaran newsletter, percobaan atau pembelian (Smith \& Zook, 2011, p. 240).

Kontrol meliputi beragam area riset pasar, jadi sistem pengukuran harus dibangun dalam perencanaan. Perencanaan adalah proses yang berulang (Smith \& Zook, 2011, p. 243).

\section{Place Branding}

Place branding adalah aktifitas pemasaran yang (1) mendukung penciptaan nama, simbol, logo, tanda kata atau grafis yang keduanya mengidentifikasi dan mendiferensiasikan suatu destinasi, (2) menyampaikan janji dari pengalaman travel yang mudah diingat yang secara unik terasosiasi dengan suatu destinasi, dan (3) yang menggabungkan dan memperkuat ingatan tentang memori yang menyenangkan dari pengalaman destinasi, semuanya dengan tujuan untuk menciptakan citra yang dapat mempengaruhi keputusan konsumen untuk mengunjungi destinasi atau sebagai perbandingan dengan alternatif lain (Govers \& Go, 2009, p. 13-14).

Place branding merupakan sebuah proses mem-branding suatu tempat yang dapat diaplikasikan juga pada negara. Place branding ini merupakan aktifitas penciptaan nama yang dapat memberikan diferensiasi dengan kompetitor yang bertujuan untuk menciptakan citra dan keputusan konsumen. Konsep place branding ini digunakan karena dapat menggambarkan konsep mem-branding Negara seperti yang dilakukan Kemenpar melalui Wonderful Indonesia. 
Terdapat sebuah model dalam manajemen place branding yang disebut sebagai "strategic place brand management model". Model tersebut mengusulkan dan kemudian secara empiris menguji sepuluh komponen dari proses manajemen tempat. Penelitian empiris kami, yang dilakukan dengan praktisi place branding dan berkaitan dengan berbagai kota dan wilayah, menegaskan/mengesahkan semua komponen dalam model teoretis sebagai bagian konstituen dari proses manajemen place brand, tetapi hanya menegaskan/mengesahkan secara parsial hubungan dalam model teoretis (Kavaratzis, Warnaby, Ashworth, 2015, p. 87). Komponen dalam strategic place brand management model ini adalah brand infrastructure, brand leadership, stakeholders management, brand articulation, brand identity, brand architecture, brand communication, word of mouth, brand experience, dan brand evaluation.

\section{METODOLOGI PENELITIAN}

Penelitian ini menggunakan paradigma konstruktivistik karena dapat memberikan gambaran terkait bagaimana Kemenpar melakukan usaha untuk mengkonstruksi masyarakat dengan menggunakan komunikasi pemasaran untuk memperkenalkan produknya yaitu Wonderful Indonesia sebagai place branding Indonesia.

Penelitian ini menggunakan metode kualitatif dengfan strategi studi kasus karena penelitian ini berusaha mengeksplorasi sebuah proses dan memahami bagaimana perencanaan komunikasi pemasaran yang dilakukan oleh Kemenpar melalui Wonderful Indonesia sebagai place branding Indonesia dengan mengajukan pertanyaan-pertanyaan, mengumpulkan data secara spesifik dan menganalisis data sehingga didapatkan hasil yang mendalam.

Dalam penelitian ini metode pengumpulan data yang digunakan adalah metode wawancara dengan narasumber utama yaitu pihak Kementerian Pariwisata RI yaitu orang-orang yang berada dalam Deputi Pengembangan Pemasaran II, Asdep Strategi \& Komunikasi Pemasaran II yang terlibat secara langsung dengan kegiatan komunikasi pemasaran Wonderful Indonesia.

Penelitian ini menggunakan seluruh proses analisis data yang dikemukakan oleh Creswell di atas, mulai dari mengolah dan mempersiapkan data; membaca keseluruhan data; Menganalisis lebih detail dengan meng-coding data; menerapkan proses coding untuk mendeskripsikan setting, orang-orang, kategori-kategori, dan tema-tema yang akan dianalisis; menyajikan kembali deskripsi dan tema-tema dalam narasi atau laporan kualitatif; hingga menginterpretasi atau memaknai data.

Penelitian ini menggunakan triangulasi untuk membantu menguji validitas datanya. Triangulasi yang digunakan yaitu triangulasi data yaitu dengan menggabungkan metode wawancara dengan berbagai narasumber dengan observasi dan pengumpulan data 
sekunder seperti data-data terkait, konsep-konsep, dokumentasi, dan lain sebagainya kemudian dijadikan alat ukur untuk menguji vailditas dari hasil penelitian

\section{HASIL DAN PEMBAHASAN}

\section{Perencanaan Komunikasi Pemasaran}

The 3Ms

Dari keseluruhan penjelasan tentang the $3 M s$, dapat disimpulkan bahwa dalam kegiatan komunikasi pemasaran Wonderful Indonesia, Kemenpar turut menggunakan tiga sumber daya kunci yaitu sumber daya manusia, anggaran, dan waktu untuk mendukung kegiatan komunikasi pemasaran. Berkaitan dengan penggunaan sumber daya manusia, Kemenpar memang menggunakan orang internal sebagai tenaga utama, namun Kemenpar turut merekrut orang eksternal seperti agensi untuk mengerjakan hal yang berkaitan dengan teknologi digital dan konsultasi kegiatan komunikasi pemasaran. Untuk penentuan anggaran, sebagai sebuah kementerian, anggaran sudah ditentukan oleh Kementerian Keuangan, namun Kemenpar tetap menyusun anggaran terlebih dahulu berdasarkan kegiatan yang akan dilakukan. Untuk penentuan waktu, dalam Kemenpar perencanaan dilakukan untuk kegiatan selama setahun kedepan. Perencanaan mulai disusun setiap pertengahan tahun.

\section{SOSTAC}

Dari penjelasan tentang SOSTAC di atas, mulai dari analisis situasi, objektif, strategi, taktik, implementasi dan kontrol, Kemenpar terbukti turut melakukan beragam langkah perencanaan komunikasi pemasaran seperti yang dirumuskan oleh Smith \& Zook. Untuk analisis situasi, Kemenpar turut mempertimbangkan aspek penting seperti kinerja pemasaran, kondisi/tren pasar, persaingan, kekuatan \& kelemahan, target pasar, dan positioning. Untuk tujuan, dalam komunikasi pemasaran Wonderful Indonesia adalah "mendatangkan 20 juta wisatawan mancanegara pada tahun 2019", kemudian tujuan komunikasinya adalah Kemenpar ingin meningkatkan brand awareness dan pengetahuan masyarakat dunia tentang Indonesia.

Strategi besar dalam komunikasi pemasaran dalam Kemenpar adalah Branding Advertising Selling (BAS) yang akan selalu berjalan beriringan. Kemenpar sebagai pemilik brand Wonderful Indonesia, tidak hanya melakukan branding untuk membesarkan nama Wonderful Indonesia, namun juga berusaha dan turun langsung untuk menjual destinasi pariwisata seperti dengan mengadakan salesmission, pameran, dan lain-lain. Hal ini menunjukkan bahwa Kemenpar turut berusaha berkontribusi tidak hanya untuk agar Wonderful Indonesia menjadi terkenal, namun juga agar destinasi Indonesia menjadi laku di pasaran.

Taktik dalam bidang komunikasi digital adalah membuat konten yang atraktif di berbagai media digital untuk menarik perhatian; menggunakan situs web dan media sosial; 
memasang iklan di media digital berbayar maupun tidak berbayar; mengembangkan promosi digital melalui Generasi Pesona Indonesia (GenPi) dan Generasi Wonderful Indonesia (GenWi); bekerjasama dengan industri airlines untuk adanya program promo; dan mengembangkan destinasi digital (destinasi yang instagrammable). Taktik dalam bidang komunikasi multimedia yaitu memasang logo dan materi promosi pada tv, majalah, out of home, bus; melakukan kerjasama co-branding dan mengembangkan nomedic tourism (pariwisata yang tidak permanen/dapat berpindah-pindah). melakukan salesmission dan berpartisipasi pada pameran pariwisata.

Implementasi dalam media digital adalah pemasangan iklan pada situs $w e b$, media sosial, dan media digital berbayar (Google+, TripAdvisor, Youtube), pemanfaatan situs web untuk pengembangan kerjasama dengan industri airlines atau industri hotel, pengembangan destinasi digital melalui media digital dengan membuatkan pasar destinasi pada media digital, pengembangan Genpi dan GenWi. Implementasi dalam multimedia meliputi pemasangan iklan TVC dan program pada TV; pemasangan materi promosi pada media cetak (majalah \& Koran), dan media out of home (billboard, wrapping bus, video tron); sales promotion dan personal selling dilakukan melalui salesmission dan pameran pariwisata, event marketing \& sponsorhip dilakukan dengan menggelar banyak event besar seperti ITB Berlin, ATM Dubai, dan juga mensponsori event-event seperti Java Jazz.

Kontrol dalam media digital lebih mudah dilakukan seperti pemasangan materi promosi pada Google dan TripAdvisor akan selalu ada report yang dapat dilihat, kemudian dapat juga dilihat dari jumlah pengunjung situs web atau pembaca konten dalam situs web, untuk media sosial dapat dilihat dari engagement yang ada seperti jumlah likes dan comments. Kontrol dalam multimedia dilakukan dengan melihat ratings pada iklan di tv, melihat readership dari media cetak, serta dengan melaksanakan monitoring dan evaluasi (monev) setiap selesai melaksanakan suatu kegiatan.

\section{Place Branding}

Berdasakan penjelasan di atas berkaitan dengan penggambaran sepuluh komponen place branding dalam Wonderful Indonesia, dapat diketahui bahwa Wonderful Indonesia dapat memenuhi semua komponen yang diperlukan untuk mem-branding sebuah tempat atau negara. Untuk brand infrastructure (Indonesia masih belum siap terutama dari sisi transportasi yang masih terbatas), brand leadership (Kemenpar turut bekerjasama dengan stakeholders spt dinas pariwisata, industri, penduduk, komunitas), stakeholders management (stakeholders turut mendukung komunikasi pemasaran \& branding Wonderful Indonesia), brand identity (five wonders yang meliputi sisi natural, adventure, modern, sensory, dan cultural), brand articulation (logo dengan gambar burung dan lima warna yang merepresentasikan negara Indonesia). Brand architecture (mengelola brand daerah dengan masih senada dengan brand Wonderful Indonesia), brand communication (melalui BAS), brand experience (pengalaman dan kesan bahwa Indonesia sangat indah, kaya, dan beragam, dan banyak yang bisa dilakukan di Indonesia), word of mouth 
(Famtrip, dan melalui media digital), brand evaluation (pengalaman bahwa Indonesia indah, kaya, dan beragam sudah bisa tersampaikan, dilihat dari indeks prestasi yang meningkat, turis sudah banyak yang sadar dengan Indonesia dan destinasinya.

\section{SIMPULAN}

Penelitian ini bertujuan untuk menggambarkan perencanaan komunikasi pemasaran dari brand Wonderful Indonesia yang juga merupakan place branding untuk Negara Indonesia. Kemudian, dari penelitian yang telah dilakukan terdapat beberapa kesimpulan yang ditemukan sebagai berikut :

1. Kemenpar turut melakukan semua langkah perencanaan komunikasi pemasaran seperti konsep yang diungkapkan oleh Smith \& Zook, 2011, yaitu The 3Ms (men, money, minutes) dan SOSTAC (situation analysis, objective, strategy, tactic, action, dan control).

2. Sumber daya manusia yang digunakan adalah orang internal dan eksternal dimana orang eksternal digunakan untuk pekerjaaan konsultasi dan pemanfaatan media digital.

3. Kemenpar turut mempertimbangkan aspek penting dalam analisis situasi seperti kinerja pemasaran, kondisi/tren pasar, persaingan, kekuatan \& kelemahan, target pasar, dan positioning.

4. Tujuan dalam komunikasi pemasaran Wonderful Indonesia adalah "mendatangkan 20 juta wisatawan mancanegara pada tahun 2019", kemudian tujuan komunikasinya adalah Kemenpar ingin meningkatkan brand awareness dan pengetahuan masyarakat dunia tentang Indonesia.

5. Strategi besar dalam komunikasi pemasaran dalam Kemenpar adalah Branding Advertising Selling (BAS) yang akan selalu berjalan beriringan. Branding dilakukan dengan memasang logo Wonderful Indonesia di banyak tempat dan pada berbagai media dengan tujuan membangun brand awareness; Advertising dilakukan dengan memasang iklan atau materi promosi pada multimedia dan digital; Selling dilakukan dengan menggelar pameran atau event pariwisata, melakukan salesmission. Kemenpar sebagai pemilik brand Wonderful Indonesia, tidak hanya melakukan branding untuk membesarkan nama Wonderful Indonesia, namun juga berusaha dan turun langsung untuk menjual destinasi pariwisata seperti dengan mengadakan salesmission, pameran, dan lain-lain. Hal ini menunjukkan bahwa Kemenpar turut berusaha berkontribusi tidak hanya untuk agar Wonderful Indonesia menjadi terkenal, namun juga agar destinasi Indonesia menjadi laku di pasaran.

6. Taktik dalam komunikasi pemasarannya adalah membuat konten yang atraktif di berbagai media digital untuk menarik perhatian; memasang iklan di media digital berbayar maupun tidak berbayar; bekerjasama dengan industri airlines untuk adanya program promo; mengembangkan destinasi digital (destinasi yang instagrammable); dan mengembangkan nomedic tourism. 
7. Implementasi kegiatan komunikasi pemasarannya adalah pemasangan iklan pada situs web, media sosial, dan media digital berbayar (Google+, TripAdvisor, Youtube); pengembangan destinasi digital melalui media digital dengan membuatkan pasar destinasi pada media digital; melakukan salesmission dan pameran pariwisata; menggelar event besar seperti ITB Berlin, ATM Dubai; dan juga mensponsori event-event seperti Java Jazz.

8. Kontrol dalam media digital lebih mudah dilakukan seperti pemasangan materi promosi pada Google dan TripAdvisor akan selalu ada report yang dapat dilihat, kemudian dapat juga dilihat dari jumlah pengunjung situs web atau pembaca konten dalam situs web, untuk media sosial dapat dilihat dari engagement yang ada seperti jumlah likes dan comments.

9. Teridentifikasi sepuluh komponen yang ada dalam model manajemen strategi place brand yaitu brand infrastructure, brand leadership, stakeholders management, brand identity, brand articulation, brand architecture, brand communication, brand experience, word of mouth, dan brand evaluation.

10. Perencanaan komunikasi pemasaran yang telah disusun mulai dari analisis situasi, objektif, strategi, taktik, implementasi, dan kontrol dapat mendukung place branding Indonesia dengan memenuhi sepuluh komponen place branding yang ada.

\section{DAFTAR PUSTAKA}

Ashworth, G. \& Kavaratzis, M. (2010). Towards Effective Place Brand Management: Branding European Cities and Regions. Cheltenham: Edward Elgar.

Antara News. (2016, April 24). Kemenpar terapkan strategi penguatan komunikasi pemasaran - ANTARA News. [online] Available at: https://www.antaranews.com/berita/557015/kemenpar-terapkan-strategipenguatan-komunikasi-pemasaran [Accessed 25 Mar. 2018].

Barat, P. (2017, August 25). Menpar Sebut Brand Wonderful Indonesia Sudah Dikenal Dunia. [online] Jabarprov.go.id. Available at: http://www.jabarprov.go.id/index.php/news/24635/2017/08/25/MenparSebut-Brand-Wonderfull-Indonesia-Sudah-Dikenal-Dunia [Accessed 10 Mar. 2018].

Belch, G. E \& Belch, M. A. (2012). Advertising and Promotion : An Intergrated Marketing Communications Perspective. Singapore: Mc Graw Hill Companies.

Bella, A. (2017, December 28). Melihat Tren Wisatawan Nusantara Tahun 2017. [online] Marketeers - Majalah Bisnis \& Marketing Online - Marketeers.com. Available at: http://marketeers.com/melihat-tren-wisatawan-nusantara-tahun-2017/ [Accessed 24 Mar. 2018]

Bungin, Burhan. (2008). Sosiologi Komunikasi: Teori, Paradigma, dan Diskursus Teknologi Komunikasi di Masyarakat. Jakarta: Kencana Prenada Media Group. 
Cangara, H. (2014). Pengantar Ilmu Komunikasi. Depok: PT Rajagrafindo Persada.

Chiaravalle, B. \& Schenck, B. F. (2015). Branding for Dummies, $2^{\text {nd }}$ Edition. Hoboken: John Wiley \& Sons, Inc.

Clow, K. \& Baack, D. (2010). Integrated Advertising, Promotion, and Marketing Communications, fourth Edition. Canada: Pearson.

Creswell, John. (2014). Research Design: Pendekatan Kualitatif, Kuantitatif, dan Mixed. Jogjakarta: Pustaka Pelajar.

Davis, M. (2009). The Fundamental of Branding. Switzerland: AVA Publishing SA.

Dinnie, K. (2008). Nation Branding. Burlington: Elsevier.

Farhan, A. (2016, December 21). Pariwisata Indonesia Raih 31 Penghargaan di 22 Negara Selama 2016. [online] detikTravel. Available at: https://travel.detik.com/travelnews/d-3377458/pariwisata-indonesia-raih-31-penghargaan-di-22-negaraselama-2016 [Accessed 10 Mar. 2018].

Fill, C. (2009). Marketing Communications: Interactivity, Communities, and Content, Fifth Edition. Harlow: Prentice Hall.

GoAceh. (2017, March 10). Bus Wonderful Indonesia Hebohkan ITB Berlin, Ini 7 Skenario Menpar Arief Yahya. [online] Available at: https://www.goaceh.co/berita/baca/2017/03/10/bus-wonderful-indonesiahebohkan-itb-berlin-ini-7-skenario-menpar-arief-yahya\#sthash.ab7Bo7fw.dpbs [Accessed 10 Mar. 2018].

Govers, R., \& Go, F. (2009). Place Branding: Glocal, Virtual and Physical Identities, Constructed, Imagined and Experienced. Hampshire: Palgrave Macmillan.

Gumelar, G. (2107, October 19). Kemenpar Klaim Pariwisata Jadi Kontributor Utama Devisa. [online] CNN Indonesia. Available at: https://www.cnnindonesia.com/ekonomi/20171018180443-78-

249279/kemenpar-klaim-pariwisata-jadi-kontributor-utama-devisa [Accessed 10 Mar. 2018].

Hakim, L. (2010). INDUSTRI PARIWISATA DAN PEMBANGUNAN NASIONAL. [online] Jurnal.stieama.ac.id. Available at: http://jurnal.stieama.ac.id/index.php/ama/article/view/18/16 [Accessed 10 Mar. 2018].

Halloran, T. (2014). Romancing The Brand: How Brands Create Strong, Intimate Relationship with Consumers. San Francisco: Jossey-Bass.

Herdiansyah, Haris. (2010). Metodologi Penelitian Kualitatif: Untuk Ilmu-ilmu Sosial. Jakarta: Penerbit Salemba Humanika. 
Hotel Management. (2015). Perkembangan Pariwisata Indonesia. [online] Available at: https://hotel-management.binus.ac.id/2015/11/18/perkembangan-pariwisataindonesia/ [Accessed 10 Mar. 2018].

Ibrahim, Nita Puspasari. (2014). Komunikasi Pemasaran Yang Efektif pada Sistem Open Government (Studi Kualitatif Pada Program Open Government Indonesia Di Unit Kerja Presiden Bidang Pengawasan Dan Pengendalian Pembangunan). E-journal Ilmiah Universitas Indonesia. Dikutip dari http://lib.ui.ac.id/file?file=digital/2016-4/20404699-MKNita\%20Puspasari\%20Ibrahim.pdf

Id.beritasatu.com. (2014, December 30). Pesona Indonesia dan Wonderful Indonesia Place branding Wisata / Investor Daily. [online] Available at: http://id.beritasatu.com/home/pesona-indonesia-dan-wonderful-indonesiacountry-branding-wisata/101610 [Accessed 10 Mar. 2018].

Instran.org. (2016). TRANSPORTASI DAN PARIWISATA. [online] Available at: http://instran.org/index.php/component/content/article/67-catatan/8132transportasi-dan-pariwisata [Accessed 10 Mar. 2018].

Investments, I. (2016). Industri Pariwisata Indonesia / Indonesia Investments. [online] Indonesia-investments.com. Available at: https://www.indonesiainvestments.com/id/bisnis/industri-sektor/pariwisata/item6051? [Accessed 10 Mar. 2018].

Jurnal Unila. (n.d). no title. Dikutip dari http://digilib.unila.ac.id/302/12/BAB\%20III.pdf

Kabarsurabaya.com. (2017, Sept 6). Kabar Surabaya » Singapore Tourism Board Luncurkan Brand Baru, Passion Made Possible dan Buka Cabang di Surabaya. [online] Available at: http://kabarsurabaya.com/2017/09/06/singaporetourism-board-luncurkan-brand-baru-passion-made-possible-dan-buka-cabangdi-surabaya/ [Accessed 24 Mar. 2018].

Kavaratzis, M., Warnaby, G., \& Ashworth, G. J. (2015). Rethink Place Branding: Comprehensive Brand Development for Cities and Regions. New York: Springer.

Keller, K.L. (2008). Strategic Brand Management. Upper Saddle River: Pearson Prentice Hall.

Kemenpar. (2017). Brand and Desain Application Guidelines. Data Internal Kemenpar (Terlampir)

Kemenpar.go.id. (2017). Cite a Website - Cite This For Me. [online] Available at: http://kemenpar.go.id/userfiles/12_\%20Lapbul\%20Des\%202017\%20(Angka\% 20Revisi).pdf [Accessed 10 Mar. 2018].

Kemenpar.go.id. (2015). KEMENPAR. [online] Available at: http://www.kemenpar.go.id/asp/detil.asp?c=7\&id=2899 [Accessed 10 Mar. 2018]. 
Kotler, P., Keller, K.L., Ang, S.H., Leong, S.W., \& Tan, C.T. (2012). Marketing Management: An Asian Perspective, $6^{\text {th }}$ Edition. Jurong: Pearson Education.

Kotler, P. \& Armstrong, G. (2016). Principles of Marketing. Harlow: Pearson Education Limited.

Liputan6.com. (2015, January 4). Pesona Indonesia Hadir Dampingi Wonderful Indonesia. [online] Available at: http://lifestyle.liputan6.com/read/2155471/pesonaindonesia-hadir-dampingi-wonderful-indonesia [Accessed 10 Mar. 2018].

Liputan6.com. (2017, December 5). Wonderful Indonesia Kembali Tebar Pesona di Melbourne. [online] Available at: http://lifestyle.liputan6.com/read/3185150/wonderful-indonesia-kembalitebar-pesona-di-melbourne [Accessed 24 Mar. 2018].

Littlejohn, S. W \& Foss, K. A. (2009). Teori Komunikasi. Jakarta: Salemba Humanika.

Lspr.edu. (2014, August 20). Humas pada Organisasi Non Profit / Prita Kemal Gani. [online] Available at: http://www.lspr.edu/pritakemalgani/humas-padaorganisasi-non-profit/ [Accessed 10 Mar. 2018].

Marketplus. (2017, February 16). Kunjungan Wisatawan ke Singapura Raih Angka Tertinggi dalam Sejarah. [online] Available at: http://marketplus.co.id/2017/02/kunjungan-wisatawan-ke-singapura-raihangka-tertinggi-dalam-sejarah/ [Accessed 24 Mar. 2018].

Media, K. (2014, December 24). Peluncuran "Wonderful Indonesia" dan "Pesona Indonesia" - Kompas.com. [online] KOMPAS.com. Available at: http://travel.kompas.com/read/2014/12/24/164500827/Peluncuran.Wonderf ul.Indonesia.dan.Pesona.Indonesia. [Accessed 10 Mar. 2018].

Media, K. (2017a, December 20). 7 Penghargaan Bergengsi untuk Pariwisata Indonesia Kompas.com. [online] KOMPAS.com. Available at: http://travel.kompas.com/read/2017/12/20/081600527/7-penghargaanbergengsi-untuk-pariwisata-indonesia [Accessed 10 Mar. 2018].

Media, K. (2017b, August 31). 2018, Pemerintah Fokus Kembangkan Tiga Sektor ini Kompas.com. [online] KOMPAS.com. Available at: http://ekonomi.kompas.com/read/2017/08/31/151136526/2018-pemerintahfokus-kembangkan-tiga-sektor-ini [Accessed 10 Mar. 2018].

Mediatama, G. (2008, December 23). Menpar: Program Visit Indonesia 2008 Sukses. [online] kontan.co.id. Available at: http://industri.kontan.co.id/news/menparprogram-visit-indonesia-2008-sukses [Accessed 10 Mar. 2018].

Moleong, L. J. (2012). Metodologi Penelitian Kualitatif Edisi Revisi. Bandung: PT Remaja Rosdakarya.

Neuman, W. Lawrence. (2014). Social Research Methods: Qualitative and Quantitative Approaches, Seventh Edition. Edinburg: Person New International Edition. 
Riadi, M. (2015). Pengertian dan Jenis Usaha Pariwasata. [online] KajianPustaka.com. Available at: http://www.kajianpustaka.com/2015/06/pengertian-dan-jenisusaha-pariwasata.html [Accessed 10 Mar. 2018].

Setkab.go.id. (2017). Pesona Indonesia/Wonderful Indonesia: Inspirasi di balik Jenama Pariwisata Indonesia. [online] Available at: http://setkab.go.id/pesonaindonesiawonderful-indonesia-inspirasi-di-balik-jenama-pariwisata-indonesia/ [Accessed 10 Mar. 2018].

Shimp, A. T. (2010). Integrated Marketing Communication in Advertising and Promotion. South-Western: Cengage Learning.

Simanjuntak, B.A., Tanjung, F., \& Nasution, R. (2017). Sejarah Pariwisata: Menuju Perkembangan Pariwisata Indonesia. Jakarta: Yayasan Pustaka Obor Indonesia.

Smith, PR. \& Zook, Z. (2011). Marketing Communications: Integrating Offline and Online with Social Media. London: Kogan Page.

Suara.com. (2016, April 2). Promosi Pariwisata Melalui Wonderful Indonesia. [online] Available at: https://www.suara.com/lifestyle/2016/04/02/194548/promosipariwisata-melalui-wonderful-indonesia [Accessed 24 Mar. 2018].

Tjiptono, F. (2015). Strategi Pemasaran, Edisi 4. Jakarta: CV Andi Offset.

Tourism In Frame. (2017). Sejarah Dan Perkembangan Tackline Pariwisata Indonesia Hingga Menjadi "Wonderful Indonesia". [online] Available at: https://tourisminframe.wordpress.com/2017/09/12/sejarah-danperkembangan-tackline-pariwisata-indonesia-hingga-menjadi-wonderfulindonesia/ [Accessed 10 Mar. 2018].

Tribunnews.com. (2017, November 14). Menteri Pariwisata Gandeng 20 Artis Promosi Wonderful Indonesia - Tribunnews.com. [online] Available at: http://www.tribunnews.com/nasional/2017/11/14/menteri-pariwisatagandeng-20-artis-promosi-wonderful-indonesia [Accessed 10 Mar. 2018].

Warta Ekonomi. (2017). Industri Pariwisata Indonesia Hasilkan Devisa Rp450 Triliun. [online] Available at: https://www.wartaekonomi.co.id/read160244/industripariwisata-indonesia-hasilkan-devisa-rp450-triliun.html [Accessed 10 Mar. 2018].

Wood, T. J. (2010). Communication Mosaics: An Introducing to the Field of Communication, Sixth Edition. Chapel Hill: Cengage Learning. 